\title{
Enunciación
}

http://revistas.udistrital.edu.co/ojs/index.php/enunc

\section{Lectura y comprensión de textos escritos en castellano por estudiantes sordos de educación básica y media}

\section{Reading and comprehension of written texts in the Spanish language by deaf stu- dents in $5^{\text {th }}$ through $11^{\text {th }}$ Grade}

\author{
Luz Mary Plaza Cortés ${ }^{1}$
}

Para citar este artículo: Plaza, L. M. (2015). Lectura y comprensión de textos escritos en castellano por estudiantes sordos de educación básica y media. Enunciación, 20(1), pp. 39-55.

Recibido: 30-abril-2015 / Aprobado: 25-mayo-2015

\section{Resumen}

El objetivo de esta investigación fue diseñar y ejecutar una intervención pedagógica discursiva e interactiva para facilitar la lectura y comprensión de textos explicativos en castellano escrito a un grupo de escolares sordos. Los referentes teóricos son: la comprensión textual desde la perspectiva discursiva e interactiva (Martínez, 2001, 2004, 2015); los géneros discursivos (Bajtín, 1982); código restringido y código elaborado (Bernstein, 1983) y la visión socioantropológica en la educación de los sordos (Skliar, 1997). La metodología de investigación fue cuasiexperimental y se realizó en tres fases: pretest, intervención pedagógica y postest. Los resultados muestran que la intervención sí facilitó la lectura y comprensión de textos escritos explicativos con modos de organización descriptiva y comparativa.

Palabras clave: intervención pedagógica, comprensión textual, discurso, niveles textuales, esquemas textuales.

\begin{abstract}
The goal of this investigation was to design and carry out a discursive and interactive pedagogical intervention to facilitate reading and comprehension of written explanatory texts in Spanish in a group of deaf students. The theoretical bases of the research are discursive classes (Bakhtin, 1982); textual comprehension from a discursive and interactive view point (Martínez, 2001, 2004, 2015); restricted code and elaborated code, (Bernstein, 1983) and the socio-anthropological vision for the education of the deaf (Skliar, 1977). The investigation used a quasiexperimental methodology and was carried out in three phases: pretest, pedagogical intervention, and post-test. The results show that the intervention facilitated the reading and comprehension of written explanatory texts that were descriptive or comparative.
\end{abstract}

Keywords: Pedagogical intervention, textual comprehension, discursive, textual levels, textual frameworks.

1 Doctora en Educación, Universidad del Valle, Cali, Colombia. Correo electrónico: luzplaza_c@yahoo.es 


\section{INTRODUCCIÓN}

Colombia tuvo grandes cambios en la década de los noventa que afectaron la educación de los escolares sordos. Indudablemente, un cambio político fue la Nueva Constitución de 1991, que ordena en su artículo 68: "La erradicación del analfabetismo y la educación de personas con limitaciones físicas o mentales, o con capacidades excepcionales, son obligaciones del Estado". Otro cambio fue la modernización del Estado, que mediante el Decreto 2009 de 1997 asignó nuevas funciones al Instituto Nacional para Sordos (Insor) como ente investigador y asesor del gobierno nacional en los temas de educación para la población con limitaciones auditivas.

En cumplimiento de la nueva misión, el Insor desarrolló investigaciones que orientaron al Ministerio de Educación Nacional (MEN) para ofrecer una educación bilingüe a la población sorda usuaria de la lengua de señas ${ }^{2}$, para lo cual se reconoció la lengua de señas colombiana como la primera lengua y el castellano escrito como la segunda lengua. Atendiendo a la asesoría brindada por esta institución, el MEN expidió la Resolución 1515 del año 2000, que establece los requisitos para la prestación del servicio educativo para los estudiantes sordos. Esta norma claramente expresa que se incluya en el currículo la enseñanza y el aprendizaje de la lengua castellana escrita como segunda lengua y que los escolares sordos continúen su educación en la básica secundaria y media en las instituciones públicas o privadas garantizándoles el servicio de intérpretes.

En 1996, los escolares sordos que usaban la lengua de señas ingresaron a las instituciones distritales con el servicio de intérpretes, es decir hace cerca de veinte años. Sin embargo, hasta la fecha, el Estado colombiano no tiene lineamientos para enseñar el idioma nacional a esta población;

2 La población sorda que usaba la lengua de señas estuvo marginada de la educación formal hasta antes de la Constitución de 1991. como consecuencia, existe una confusión de lo que se concibe como segunda lengua en la educación de los escolares sordos. Esto se refleja en la asignación de solo cuatro horas semanales de clase de castellano escrito, con las que se pretende enseñar la lengua nacional y erradicar el analfabetismo. No obstante, los jóvenes sordos que terminan la básica media no leen ni escriben, como lo demuestran las investigaciones realizadas con estudiantes sordos que ingresan a la educación superior (Rodríguez de Salazar, 2009).

Frente a esta problemática nos preguntamos cuál podría ser la opción pedagógica que, siendo coherente con los avances en las ciencias del lenguaje y la pedagogía de la lengua, les ayudara a los escolares sordos a comprender e interpretar los tipos de textos escritos en español que se ven abocados a leer durante su escolaridad. Por este motivo, decidimos diseñar y ejecutar una intervención pedagógica discursiva interactiva pertinente para esta población, con el fin de facilitar la comprensión de textos explicativos escritos en castellano a un grupo de escolares sordos en una escuela pública (Plaza, 2015).

La intervención pedagógica discursiva e interactiva (Martínez, 2002, 2015) que desarrollamos buscó enriquecer los conocimientos previos del lector en relación con los diversos niveles de construcción del texto escrito, pues este conocimiento facilita el proceso inferencial en el momento de la comprensión textual. En la Figura 1 se observan cinco niveles textuales: enunciativo, microestructural, macroestructural, superestructural y argumental. En el primer nivel, el lector/estudiante debe identificar la situación de enunciación para hacer inferencias relacionadas con las relaciones de fuerza entre el enunciador (yo), el enunciatario (tú) y el tercero, (el tema, lo enunciado). Es decir, que el enunciado está constituido por sujetos y objetos discursivos, los cuales, en la dinámica de la enunciación, se constituyen en imágenes que representan al locutor como al interlocutor (sus intenciones, propósitos y posiciones) y al tema del discurso. 


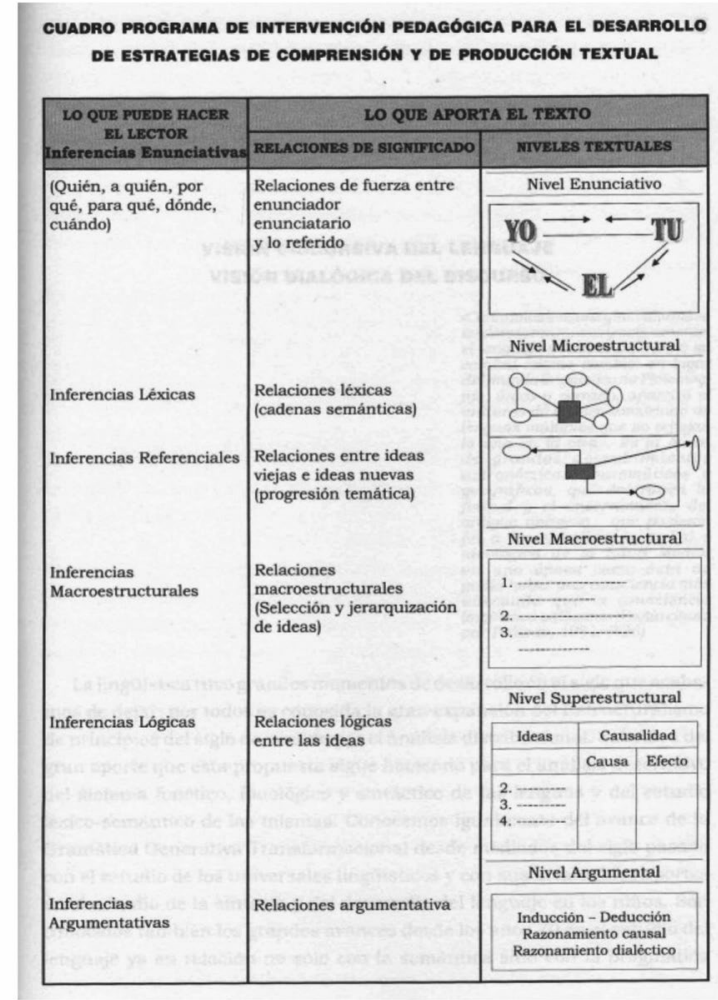

Figura 1. Programa de intervención pedagógica para el desarrollo de estrategias de comprensión y producción textual.

Fuente: tomado de Martínez (2002).

Al respecto, Martínez (2002) sostiene que para dominar el discurso escrito el sujeto acude a una competencia discursiva (enunciativa) y a una competencia comunicativa, lo que por supuesto también implica la puesta en juego de una competencia lingüística, es decir, el conocimiento y dominio de los aspectos formales de la lengua. Esto significa que en el discurso escrito converge una dinámica enunciativa y una dinámica comunicativa: en la producción de un enunciado no solo se ponen en juego unas relaciones de fuerza entre un yo, un tú y un él (sujetos discursivos), sino que también se ejecuta un acto comunicativo. En la presente investigación asumimos el discurso escrito como el producto de la interacción de individuos socialmente organizados, cuya unidad de análisis es el enunciado (Bajtín, 1982, citado por Martínez, 2002).

Es pertinente aclarar que nos centramos en desarrollar principalmente la competencia discursiva de los escolares sordos, en el entendido de que al hacerlo también estamos involucrando el desarroIlo de la competencia lingüística y comunicativa del aprendiz.

En el segundo nivel, el microestructural, el estudiante debe conocer y aprender a establecer los enlaces de cohesión léxica y gramatical para poder realizar las inferencias léxicas y referenciales. Según Van Dijk y Kintsch (1978), un buen tejido microestructural le permitirá al lector hacer una lectura fluida, no perder el hilo al desarrollo temático e interpretar las ideas de base del texto. Las proposiciones que conforman la microestructura se articulan para dar lugar al tercer nivel, el macroestructural. En este nivel se identifican las ideas principales y secundarias del texto, para esto el lector acude a las macrorreglas: omisión-selección, generalización e integración (Van Dijk, 1998). Las inferencias micro y macroestructurales son correlacionales, es decir no se dan la una sin la otra. 
El cuarto nivel, el superestructural, consiste en el esquema organizativo abstracto del texto escrito, es decir, la estructura que representa las partes en que se organiza el texto y que lo caracteriza como una narración, una descripción o una explicación, entre otras. Por último, el nivel, argumental, permite al lector realizar inferencias argumentativas gracias al conocimiento y dominio de secuencias como la deducción, el razonamiento causal, la dialéctica, entre otros.

Así, entonces, entendemos que la lectura y comprensión de un texto escrito involucra, por una parte, un nivel enunciativo, frente al cual el lector aporta inferencias que le permiten advertir quién habla en el texto, a quién, por qué se habla de determinado asunto, para qué, dónde ocurre el evento de la enunciación, es decir los puntos de vista, y las imágenes que se construyen de los sujetos discursivos en el texto; $y$, por otra parte, el conocimiento de la textualidad del texto, en otras palabras, las estructuras semánticas del texto.

El conocimiento de los niveles textuales enriquece los conocimientos previos del lector, facilitando la interacción del estudiante/lector con el texto. En este estudio asumimos la comprensión textual como una experiencia discursiva y reconocemos que el texto escrito al igual que el texto oral es interactivo (Martínez, 2002). Dado que en esta investigación nos interesan los textos que siguen el modo de organización explicativo, abordaremos sus características y las exigencias que hace al lector, pues consideramos importante hacer tomar conciencia al estudiante de esta forma de organización discursiva para mejorar su comprensión textual.

Los textos explicativos son aquellos donde el locutor construye el tema con la intención de hacer llegar la información de la manera más comprensible a su interlocutor, su función comunicativa es hacer entender un objeto, concepto, teoría, problema, fenómeno en diferentes niveles de complejidad y especificidad (Martínez, 2004).
La función social de la explicación como hecho discursivo supone una relación comunicativa asimétrica entre el locutor y el interlocutor. El primero se presenta como poseedor de un saber del cual el interlocutor carece, de este modo el locutor construye un enunciador quien expone ese saber. Martínez (2004) señala cuatro secuencias posibles que son características de los textos explicativos, a saber: descripción, comparación y contraste, problema solución y causalidad.

En nuestra intervención usamos textos explicativos con secuencias descriptivas y comparativas. Los textos explicativos con secuencia descriptiva se caracterizan por relacionar de manera temporal o secuencial hechos, fenómenos, eventos, sucesos sociales, naturales o de otra índole. En esta secuencia, el autor tiende a usar marcadores discursivos (conectores) que revelan el tipo de acto de habla general que se está desarrollando en el texto. Así, es común encontrar en este tipo de esquema discursivo marcadores como: en primer lugar, en segundo lugar, luego, después, más adelante, o acude a presentar listas de hechos, características, series de fases o etapas de algún fenómeno (social, natural).

Los textos con organización comparativa, tienden a mostrar diferencias, similitudes o semejanzas entre mínimo dos objetos temáticos que son objeto de contraste. Igualmente, se recurre al uso de marcadores discursivos tales como: mientras que, por el contrario, otra diferencia, sin embargo, no obstante, en comparación, en contraste con, mayor que, igual que, del mismo modo, etc.

De acuerdo con Martínez (2004), debido a las características del texto escrito, este hace unas exigencias al lector para que construya relaciones significativas entre los enunciados y le facilite la comprensión. Es necesario, pues, que el lector esté familiarizado con significados universales, en el sentido de que funcionen independientes del contexto, es decir, que use un código elaborado. Por lo anterior, tuvimos en cuenta las investigaciones de Bernstein (1983) sobre el 
código elaborado y restringido. Según este autor, los códigos están asociados con la clase social. La clase media tiene una tendencia a usar una orientación del significado independiente del contexto inmediato, es decir es más explícito o elaborado.

En contraste, la clase social obrera tiene una tendencia a orientar el significado más dependiente del contexto, es decir usan un código restringido, más implícito y sus significados se dan por entendidos porque se piensan que se comparten con su interlocutor.

En síntesis, Bernstein (1994, 1983) explica que la diferencia entre los niños que usan los códigos elaborados o restringidos no es una diferencia de facilidad/capacidad cognitiva, sino de reglas de reconocimiento y realización para leer el contexto, seleccionar su práctica interactiva y crear sus textos. Es decir, la problemática se presenta en el momento del niño hacer la selección de sus enunciados, no significa que el estudiante no conozca su lengua. Este investigador identificó la problemática en hablantes de la lengua inglesa y Martínez (1985) la confirmó con hablantes del castellano, entonces la problemática tampoco está relacionada con el idioma.

Finalmente, considerando que los escolares que participaron en esta investigación son sordos, tuvimos en cuenta la visión socioantropológica (Skliar, 1997), según la cual, las personas sordas no tienen deficiencias sino diferencias, es decir, vemos a los escolares sordos como sujetos con las mismas potencialidades que los oyentes, si bien usan un idioma diferente: la lengua de señas, que es visual y gestual.

\section{METODOLOGÍA}

Seleccionamos la metodología de investigación cuasiexperimental, apoyados en las investigaciones de Álvarez, (2002) y Hernández, (2002), quienes la utilizaron en sus intervenciones pedagógicas discursivas con estudiantes oyentes y mostraron resultados favorables.
El diseño de esta investigación tuvo en cuenta tres fases: en la primera se aplicaron el pretest para identificar el nivel inicial de comprensión de textos explicativos con secuencias descriptiva y comparativa, una encuesta para caracterizar a los escolares participantes, y una historieta muda para elicitar la lengua de señas. La segunda fue la intervención pedagógica; y en la tercera fase o postest se aplicó una prueba de comprensión textual con textos explicativos después de la intervención para identificar si ocurrió o no un mejoramiento en la comprensión de textos escritos.

\section{Muestra}

La investigación contó con un grupo experimental determinado por la organización ya establecida de los grados escolares, desde quinto de primaria hasta once, en una escuela pública ubicada al sur de Bogotá, en el horario de 6:20 a.m. a 12:20 p.m. La muestra para la intervención pedagógica estuvo constituida por 21 estudiantes sordos entre 14 y 21 años de edad. La intervención para leer y comprender textos escritos en castellano se ofreció en la contrajornada escolar, es decir en el horario de 1:00 p.m. a 3:00 p.m. de lunes a viernes, de abril a diciembre del año 2013. La docente que realizó la intervención pedagógica es la misma investigadora.

\section{Primera fase}

En esta fase utilizamos tres instrumentos: un pretest, una encuesta y una historieta muda para caracterizar a la población. Con el pretest se buscaba evaluar el nivel de comprensión textual inicial de los escolares sordos; para ello se aplicaron dos pruebas escritas con textos con organización superestructural explicativa: una con secuencia descriptiva y la otra con secuencia comparativa. Cada prueba constaba de diez preguntas de selección múltiple distribuidas de la siguiente manera: seis evaluaban el nivel microestructural; dos, el nivel macroestructural y dos más, el nivel enunciativo. Los valores de 
rendimiento lector se midieron en el rango de 0 a 10 puntos por cada test.

La encuesta permitió hacer una caracterización cualitativa de la población intervenida en relación con cuatro aspectos fundamentales: (i) información personal (fecha de nacimiento, dirección, edad de pérdida de la audición, forma de comunicación con los compañeros y maestros); (ii) historia escolar (el nombre de los colegios y condiciones de estudio, compañeros oyentes o sordos); (iii) información familiar (padres y hermanos sordos u oyentes y nivel de escolaridad); (iv) relación del estudiante con la lectura y la escritura (conciencia sobre competencia lectora y escritural).

Respecto a la historieta muda que usamos para elicitar la lengua de señas, consideramos relevante esta prueba porque nos permitía identificar el tipo de código que usaban los escolares (elaborado o restringido), es decir, la orientación del significado según el grado de dependencia del contexto inmediato al hacer la descripción. Para ello, la prueba de la historieta muda se basó en un experimento de Bernstein (1983) para identificar los códigos elaborados y restringidos en un grupo de escolares oyentes en Inglaterra.

El experimento consistió en entregar una historieta muda compuesta por cuatro láminas en secuencia, en las que hay dibujadas cuatro escenas que representan una situación de comunicación. La docente solicitó a los estudiantes que contaran la historia en lengua de señas colombiana a su interlocutor, quien no vio los dibujos. Las cuatro láminas se colocaron en orden delante de cada estudiante sordo, quien las observaba y luego debía decirle al interlocutor quien era un adulto sordo. La experiencia se realizó en forma individual. Cabe aclarar que los estudiantes que realizaban la actividad no tuvieron contacto con los estudiantes que esperaban su turno en el salón de clase. Se grabó el discurso en lengua de señas para hacer el análisis.

Las variables dependientes fueron las siguientes: nivel de comprensión inicial, nivel de comprensión final, mejoramiento en la comprensión. El objetivo práctico de la intervención pedagógica era mejorar la comprensión textual en los sujetos sordos, a partir de la propuesta diseñada. Para analizar o validar si había o no mejoramiento, se midió el nivel de comprensión de los sujetos al inicio y al final de la intervención.

Las variables independientes en relación con los sujetos fueron: edad cronológica, edad en que perdieron la audición, edad en que iniciaron el uso de la LSC (se refiere al momento en que el escolar usa el idioma de lengua de señas colombiana) y el grado escolar.

\section{Segunda fase}

Como se mencionó, esta fase se refiere a la intervención pedagógica, donde realizamos conversatorios con los estudiantes con tres propósitos: identificar temas de interés que nos ayudaran en la selección de los textos, observar el uso del castellano en la escuela y observar las exigencias académicas que hacen los docentes de las diferentes asignaturas.

Respecto al resultado del primer propósito, seleccionar los textos escritos con temas interesantes para los estudiantes, se pudo constatar que la clase de danzas era la de mayor preferencia, debido a las pocas exigencias académicas de esta asignatura. En general, los escolares sordos no expresaron interés por temas académicos ni de otra índole, pues no tenían intenciones de leer.

Respecto al uso del castellano, en un ejercicio de revisión de cuadernos se pudo constatar que los estudiantes: (i) no entendían los apuntes que tenían escritos en sus cuadernos y para la mayoría no eran significativos; (ii) no dieron cuenta de algunos temas de las asignaturas; (iii) los apuntes son en su mayoría ininteligibles debido a una deficiente caligrafía, inversión de letras $p / q, d / b$, entre otros. Algunos estudiantes suprimen letras, palabras e incluso frases.

El tercer propósito estuvo relacionado con las exigencias de los docentes. Un punto relevante 
fue que durante las evaluaciones trimestrales se asigna el intérprete a los escolares sordos para presentar las pruebas. En consecuencia, los estudiantes no necesitan leer las evaluaciones para responderlas, pues el intérprete de lengua de señas lee las preguntas y las opciones de respuesta, razón por la cual no se ven a abocados a enfrentar la lectura de textos escritos. Este hecho corrobora que a los estudiantes sordos se les restringe la posibilidad de comprender los usos y funciones de la escritura para acceder al conocimiento o para dar cuenta del mismo.

Estos hallazgos nos obligaron a abrir un espacio antes de iniciar la enseñanza de la lectura y la comprensión de textos explicativos. Por esta razón diseñamos y desarrollamos las unidades I y II (Tabla 1), con el propósito de enfrentar la apatía y la desmotivación por parte de los estudiantes mediante la reflexión sobre las ventajas del castellano escrito en la vida de las personas sordas.

Al finalizar la unidad II, observamos que la actitud de los estudiantes frente al texto escrito había mejorado y podíamos iniciar la lectura y comprensión con textos explicativos. Para el diseño y ejecución de las siguientes unidades, consideramos que en esta intervención se trataba de enseñar a leer y comprender textos escritos en castellano escrito como segunda lengua para los sordos, por esto no era posible que iniciáramos el programa de intervención por el nivel enunciativo, como lo propone Martínez (2002, 2015), ya que debemos enseñar primero el nivel microestructural para que el estudiante sordo establezca las relaciones entre las proposiciones y comprenda la base proposicional del texto escrito. Por otra parte, teniendo en cuenta que la intervención pedagógica se inició en abril y que el año escolar se terminaba en noviembre, decidimos trabajar únicamente tres niveles del texto escrito: (i) el nivel microestructural, (ii) el macroestructural y (iii) el superestructural.

En la Tabla 2 se observa el diseño de las unidades III, IV y V, que fue modificado durante la intervención, ya que los estudiantes tuvieron dificultad para identificar la idea principal y las ideas secundarias. El orden que seguimos para trabajar los tres niveles fue: (i) nivel microestructural, (ii) superestructural y (iii) macroestructural.

\section{Procedimiento para enseñar la unidad IV nivel microestructural}

En esta investigación tuvimos en cuenta los resultados de la prueba de elicitación de la lengua de señas, en la que usamos la historieta muda. Los resultados nos indicaron que todos los escolares tenían la tendencia al uso del código restringido. Considerando que la orientación del significado

Tabla 1. Programa de intervención pedagógica para escolares sordos (unidades I y II)

\begin{tabular}{ll}
\hline \multicolumn{1}{c}{ Unidades } & \multicolumn{1}{c}{ Contenidos } \\
\hline $\begin{array}{l}\text { Unidad I } \\
\text { La lectura y la escritura en las } \\
\text { comunidades letradas. }\end{array}$ & Las diferencias entre las comunidades orales y las comunidades letradas. \\
& Los testimonios de sordos lectores colombianos. \\
Unidad II & El libro como memoria de las comunidades letradas. \\
$\begin{array}{l}\text { Lectura y comprensión de tex- } \\
\text { tos escritos con modo narrativo. }\end{array}$ & Lectura y comprensión de seis textos escritos con modo narrativo. \\
\hline
\end{tabular}

Fuente: Plaza (2015). 
Tabla 2. Programa de intervención pedagógica para escolares sordos (unidades III, IV y V)

\begin{tabular}{llc}
\hline \multicolumn{1}{c}{ Unidades } & \multicolumn{1}{c}{ Categorías } & Exigencias para el lector \\
\hline $\begin{array}{l}\text { Unidad III } \\
\text { Niveles }\end{array}$ & $\begin{array}{l}\text { Diferenciar los niveles textuales: micro, macro y superes- } \\
\text { tructural }\end{array}$ & $\begin{array}{c}\text { Identificar y diferenciar cada } \\
\text { nivel textual }\end{array}$
\end{tabular}

Unidad IV

Nivel Microestructural
Cohesión gramatical: referencia, sustitución y elipsis. Referencia personal: ocurre cuando se reemplaza el grupo nominal por un pronombre personal, un adjetivo posesivo o un pronombre posesivo. Esta referencia puede ser anafórica o catafórica. Ejemplo: “Un día un rey salió de cacería. Él soltó a su halcón favorito para que alcanzara a una liebre".

Referencia elíptica: elide el grupo nominal y aparece explícita en la terminación verbal que conlleva las marcas de persona y número. Ejemplo: "Así cuando tú y mamá estén viejos, podré ponerles ahí la comida".

Referencia demostrativa: se usa cuando se identifica el referente según un grado de proximidad. Si se quiere indicar que se hace referencia a algo que se mencionó inmediatamente antes en el texto, se usa este, estos, estas. Ejemplo: "Desde tiempos bíblicos, pueblos, familias, tribus y otros grupos de personas han adoptado animales como símbolos particulares en sus emblemas. Al estudio de estos se le llama heráldica".

Referencia relativa: sirve para introducir expansiones de tipo explicativo y especificativo que son nuevas oraciones; esta referencia usa los pronombres relativos que, quien, cuyo, el cual, y sus correspondientes plurales. Ejemplo: "En ese momento el halcón que descansaba en su muñeca, se irguió, batió las alas y derramó el agua".

Cohesión léxica: coocurrencia y reiteración.

Coocurrencia: para mantener la cohesión léxica, el autor de un texto usa términos de contraste y de ampliación semántica para relacionar términos que pueden pertenecer al mismo campo semántico, pero no son sinónimos. En el siguiente ejemplo se observa los términos olor, receptores sensoriales, órganos olfativos, que son términos que coocurren porque son complementarios y pertenecen al mismo campo semántico aunque no son sinónimos. Ejemplo: "Cuando los seres humanos detectamos un olor se debe a la presencia de moléculas que son captadas a través de los receptores sensoriales que poseemos en nuestros órganos olfativos".

Reiteración: indica repetición de un concepto. Hay diferentes maneras de reproducir un concepto y para ello se deben establecer valores semánticos referenciales que inciden en la ampliación semántica del término en nuevos contextos, los cuales van a incidir en la manera de comprensión. La reiteración se puede dar por: (a) repetición, (b) sinonimia y (c) superordenación. Ejemplo: "El hombre suele emplear animales para que cumplan tareas útiles, así ocurre con el cormorán, ave utilizada para pescar".
Inferencias referenciales 


\begin{tabular}{|c|c|c|}
\hline Unidades & Categorías & Exigencias para el lector \\
\hline $\begin{array}{l}\text { Unidad V } \\
\text { Nivel } \\
\text { Superestructural } \\
\text { y Macroestructural }\end{array}$ & $\begin{array}{l}\text { Superestructura } \\
\text { Textos explicativos con secuencia descriptiva: se caracte- } \\
\text { rizan por relacionar de manera temporal hechos, fenó- } \\
\text { menos, sucesos sociales, entre otros. En esta secuencia el } \\
\text { autor usa marcadores discursivos como en primer lugar, en } \\
\text { segundo lugar, después entre otros, que revelan el tipo de } \\
\text { acto de habla general que está desarrollado en el texto. } \\
\text { Macroestructura: es la identificación jerárquica de las } \\
\text { ideas: el tema (idea principal) y las ideas secundarias que } \\
\text { componen el texto. } \\
\text { Macrorreglas: son operaciones de generalización semán- } \\
\text { tica que realiza el lector durante el proceso de identifica- } \\
\text { ción jerárquica de las ideas. } \\
\text { La omisión - selección permite omitir la información poco } \\
\text { relevante, redundante y no esencial del texto. } \\
\text { La generalización aunque omite información se sustituye } \\
\text { por nuevas proposiciones que evidencian un proceso de } \\
\text { abstracción. } \\
\text { La integración permite en la proposición construida substi- } \\
\text { tuir una serie de hechos por su consecuencia o su causa. }\end{array}$ & Inferencias macrosemánticas \\
\hline
\end{tabular}

Fuente: Plaza (2015).

de este grupo de escolares es restringido, iniciamos el trabajo pedagógico en este nivel con la lectura de proposiciones cercanas al contexto inmediato de los estudiantes. El trabajo se inició con la lectura y comprensión de proposiciones relacionadas con el contexto inmediato de los estudiantes. Ejemplo: Natalia estudia en el colegio San Francisco. Ella está en octavo grado. La profesora usó las flechas como marcas visuales para establecer las relaciones entre las proposiciones como lo muestra esta ilustración.

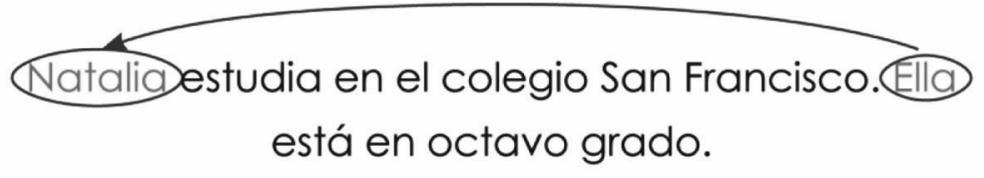

Figura 2. Nivel microestructural. Ejemplo de referencia anafórica.

Fuente: Plaza (2015). 
Este tipo de ejemplos permitió que los estudiantes estuvieran atentos y con una actitud positiva para aprender, porque era algo conocido que ellos podían leer y comprender. Luego la profesora explicó la relación del nombre Natalia con el pronombre ella. Seguidamente, encerró en un círculo de color el pronombre y con una flecha indicó la relación que se establece con el nombre. La flecha señala la relación que se establece entre el referente y el pronombre. Posteriormente, presenta el siguiente texto.

\section{Natalia estudia en el colegio San Francisco. Natalia está en octavo grado.}

La docente explica la función de los pronombres, la cual consiste en evitar las repeticiones y mantener la cohesión del texto. También este ejemplo permite explicar la referencia anafórica, ya que el pronombre ella depende del nombre $\mathrm{Na}$ talia, que fue nombrado antes.

A continuación se presentó otro ejemplo de una referencia catafórica en la cual el pronombre él depende o reemplaza a Juan Manuel Santos, que se encuentra después, como lo indica la flecha.
Con este mismo procedimiento se explicaron las relaciones léxicas y referenciales del nivel IV de la Tabla 2. Es importante tener un variado número de proposiciones con temas del contexto inmediato para jalonar gradualmente a los estudiantes hacia la lectura y comprensión de textos explicativos.

El elemento funcional de la flecha la utilizamos para que el estudiante visualizara los lazos formales que unen las proposiciones relacionadas con un antes o un después para encontrar el significado en el texto y establecer las inferencias adecuadas.

\section{Procedimiento para trabajar la unidad V la superestructura y la macroestructura del texto explicativo con secuencia descriptiva}

El objetivo de esta unidad era distinguir diferentes tipos de superestructura en los textos explicativos, con secuencia descriptiva y con secuencia comparativa. Por razones de espacio, presentamos un ejemplo del procedimiento de esta unidad para trabajar el texto explicativo con secuencia descriptiva. El procedimiento se realizó de la siguiente manera: se inició con la presentación de un texto escrito explicativo con secuencia descriptiva que

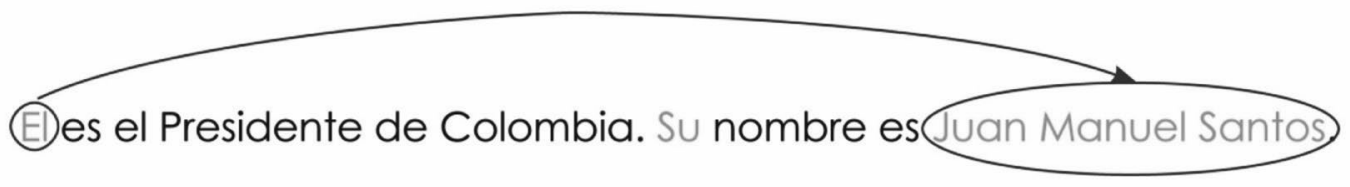

Figura 3. Nivel microestructural. Ejemplo de referencia catafórica.

Fuente: Plaza (2015). 
tocios los alimentos estál formades por tres sustancias que son

uecestatias parta que uuestio organismo funcione bien. Una de estas

sustancias selu las proteínas. Su falta nos puede producir muchas

enfermedades. Fodenos encentrar las proteínas en alimentos como la

catue, los hueves, el pescado o la leche, entre otros. Otra de las sustancias

que fortutin los alimentos son las grasas. Estas sustancias están en

altumentes ceme el acelte, los fiutos seces y el cerdo. Tomar excesivas

grasas uos puede plocucit diversas enfermedades tales cemo la obesidad que es uut enfermedad ocastonada per toutar demastados allimentos cen grasas. La tercera de estas sustancias sen los hidratos de carbono. Los hidratos de carbono sell thecestalios, pero the en mucha cantidad. Les encertuatuos elt alimentos como el par, las papas, el azúcar y las frutas firescas. Es imyer tante para la salud comer alimentos que tengan estas tres sustancias adecuadas.

Figura 5. Texto explicativo con secuencia descriptiva.

Fuente: tomado de Vidal (1990). Señalización del campo semántico y de los marcadores discursivos por Plaza (2015).

integraba la señalización del campo semántico y de los conectores discursivos (Figura 5).

Se orientó a los estudiantes para que observaran la señalización y la relacionaran con el título para identificar tanto el área del conocimiento al que pertenece el texto como el campo semántico del tema tratado.

Se realizó la lectura del texto en lengua de señas por parte de la docente, con el fin de mostrar la relación microestructural a través de las ideas y facilitar la comprensión en castellano escrito. La docente realizó la relectura del texto, enfatizando en las relaciones léxicas y referenciales que se utilizan, y así orientar la atención de los estudiantes para que logren la identificación de las relaciones de significado que se construyen en la microestructura del texto.

En el tablero se hizo la reconstrucción del mapa textual del texto explicativo-descriptivo (Figura 6) utilizando tiras de papel con las proposiciones del texto y, simultáneamente, se presentó el texto completo en la pantalla de un televisor, con el fin de lograr la reconstrucción por partes y mostrar las características de esas partes, que es lo representativo de este tipo de texto.

La estrategia de reconstrucción del texto y la identificación visual de la posición jerárquica de las proposiciones en el mapa textual permitió establecer la relación entre ideas principales y secundarias.

\section{RESULTADOS}

La media del pretest con texto descriptivo fue 4.0/10 y la media del pretest con secuencia comparativa fue de 3.80/10. A partir del análisis cuantitativo del pretest, se evidencia que las variables independientes edad, curso, edad de pérdida de audición y edad del primer uso de LSC en la escuela no tienen relación con el nivel de comprensión textual. Igualmente, se aprecia que todos los estudiantes Ilegaban aproximadamente con un mismo nivel en sus capacidades para comprender textos escritos en su segunda lengua, específicamente los explicativos con secuencias descriptiva y comparativa, por lo cual pudimos agrupar a toda la población para la intervención pedagógica en el horario de 1 a 3 de la tarde. Aunque también organizamos espacios académicos en la jornada de 


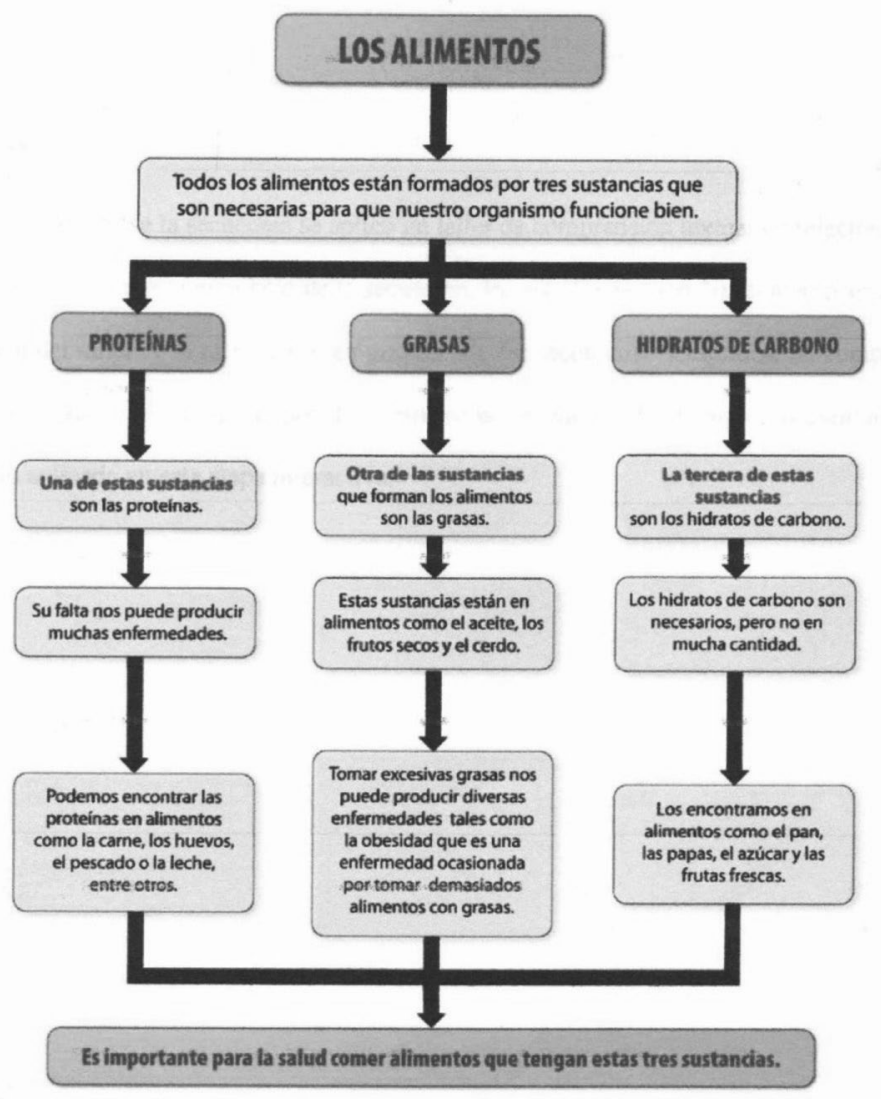

Figura 6. Mapa textual del texto explicativo Los alimentos.

Fuente: Plaza (2015).

la mañana para trabajar los estándares de cada grado escolar en grupos separados.

En la Tabla 3 se presentan los datos de la encuesta sobre la información personal, específicamente en los ítems de la edad en que perdieron la audición y la edad en que iniciaron el uso de la lengua de señas. Un dato importante es la extraedad, por ejemplo la estudiante de quinto de primaria tenía 17 años, algunos estudiantes de once tenían 21 años, entre otros. El 52\% de la población que participó en la investigación nació sorda, lo que corresponde a un poco más de la mitad de los participantes. El 33\% perdió la audición antes de los 24 meses. Esto nos permite inferir que los programas para detectar la sordera en Bogotá están funcionando. Sin embargo, el Estado no tiene directrices ni programas de atención para atender a los menores con sordera antes de los 5 años de edad. Como consecuencia el ingreso a la básica primaria es tarde, más el agravante de no tener la lengua de señas. Tal es el caso del sujeto 1 de la Tabla 3, a quien se le identificó la sordera en el momento de nacer y hasta los 12 años ingresó al grado primero por falta de orientación a la familia.

Otro dato relevante fue que las familias de todos los escolares sordos que participaron en la investigación son oyentes y ninguno tiene familiares con sordera. Lo anterior permitió confirmar que antes de llegar a la escuela, ningún estudiante usó la lengua de señas como idioma para comunicarse. En sus casas acudían a señas "caseras" como forma de comunicación y solo hasta que ingresaron al 
Tabla 3. Datos de la encuesta

\begin{tabular}{|c|c|c|c|c|c|}
\hline Estudiante & Curso & $\begin{array}{c}\text { Fecha de } \\
\text { nacimiento }\end{array}$ & $\begin{array}{c}\text { Edad día de } \\
\text { la encuesta } \\
05 / 15 / 2013\end{array}$ & $\begin{array}{l}\text { Edad (meses) } \\
\text { pérdida audición }\end{array}$ & $\begin{array}{l}\text { Edad primer } \\
\text { uso LSC en } \\
\text { educación } \\
\text { formal }\end{array}$ \\
\hline 1 & 5 & $7 / 23 / 1996$ & 17.4 & 0 & 12 \\
\hline 2 & 6 & $3 / 2 / 1998$ & 15.8 & 72 & 15 \\
\hline 3 & 6 & 9/21/1999 & 14.2 & 60 & 13 \\
\hline 4 & 7 & 8/15/1996 & 17.3 & 0 & 12 \\
\hline 5 & 7 & $6 / 24 / 1997$ & 16.4 & & 15 \\
\hline 6 & 7 & 1/1/1998 & 15.9 & 0 & 15 \\
\hline 7 & 7 & 1/19/1998 & 15.9 & 0 & 6 \\
\hline 8 & 7 & 5/3/1999 & 14.6 & 24 & 7 \\
\hline 9 & 7 & 6/20/1999 & 14.5 & 12 & 6 \\
\hline 10 & 8 & 6/5/1995 & 18.5 & 6 & 9 \\
\hline 11 & 8 & 6/30/1995 & 18.4 & 6 & 7 \\
\hline 12 & 8 & 2/21/1999 & 14.8 & 18 & 5 \\
\hline 13 & 9 & 1/7/1994 & 19.9 & 3 & 10 \\
\hline 14 & 10 & 6/21/1994 & 19.4 & 0 & 7 \\
\hline 15 & 10 & 5/29/1995 & 18.5 & 0 & 6 \\
\hline 16 & 10 & 6/30/1995 & 18.4 & 0 & 10 \\
\hline 17 & 10 & 7/13/1995 & 18.4 & 8 & 7 \\
\hline 18 & 10 & 2/20/1996 & 17.8 & 0 & 4 \\
\hline 19 & 11 & 4/11/1992 & 21.6 & 0 & 8 \\
\hline 20 & 11 & 7/3/1992 & 21.4 & 0 & 8 \\
\hline 21 & 11 & 11/15/1992 & 21.0 & 0 & 10 \\
\hline
\end{tabular}

colegio conocieron y empezaron el uso de la lengua de señas.

Se observa que el 9\%, es decir 2 estudiantes, iniciaron la adquisición de la primera lengua, o sea la lengua de señas, entre los 4 y 5 años. El $43 \%$ iniciaron el aprendizaje de la lengua de señas entre los 6 y 8 años de edad, lo cual significa que es una edad tardía para empezar a adquirirla. Esto confirma que hay un vacío estatal en la atención de los niños en la primera infancia.

El $48 \%$ de los sujetos de la muestra inician la adquisición de la lengua de señas entre los 9 y 15 años. Estos estudiantes asistieron a las escuelas regulares junto con los estudiantes oyentes sin considerar sus necesidades educativas especiales. Debido al bajo rendimiento académico, fueron reubicados en la institución educativa que ofrece el servicio del programa de inclusión para sordos.

Este panorama en general demuestra que los escolares sordos ingresan a la escuela sin tener el dominio de una lengua. En consecuencia, durante la básica primaria los niños sordos deben adquirir la lengua de señas, razón por la cual los tiempos para la enseñanza de los contenidos curriculares son afectados, pues al finalizar la escuela elemental no saben leer ni escribir el idioma nacional, esto es, el castellano escrito. 
Con respecto al nivel educativo de la familia, la encuesta informa que el $14 \%$ de las madres de familia no tienen ningún tipo de estudios, el $48 \%$ solo ha cursado la primaria, el $24 \%$ ha terminado el bachillerato y el $14 \%$ restante ha realizado estudios técnicos. El 15\% de los padres de familia no tienen ningún tipo de estudios, el 55\% terminaron primaria, el 30\% cursaron el bachillerato y ninguno realizó estudios técnicos.

Respecto a la prueba de elicitación de la lengua de señas, se pudo observar que los escolares tienen tendencia al código restringido. Algunas de las características de este código son acudir al uso frecuente de deícticos y no contextualizar al interlocutor, dando por entendido que él también está viendo la lámina. En otros casos se observó que los estudiantes sordos tienden a asumir el rol de los personajes de la historieta y a expresarse en estilo directo en lugar de usar el estilo indirecto. También es frecuente el uso de sonidos, ruidos (onomatopeyas) en lugar de usar la seña que representa la acción a la que se refiere el sonido o ruido. Por ejemplo, se vocaliza el sonido ipum; en lugar de la seña del verbo golpear o romper. Además, se notó con bastante frecuencia la aglutinación de verbos, lo cual es una evidencia de elisión de los sujetos y del predicado que suprime información relevante sobre quién realizó la acción y sobre qué o quien recae.

En síntesis, se deja implícita la información restante, característica del código restringido. Igualmente, se observa la tendencia a usar términos relacionados con su contexto inmediato, como por ejemplo usar el término mamá o papá en lugar de expresiones genéricas como hombre, mujer, señor, señora.

Estos resultados nos advirtieron que el proceso de intervención sería más complejo, ya que, según Bernstein (1983) y Martínez (1985), los estudiantes que usan un código restringido necesitan recontextualizar la información, lo cual implica un aprendizaje más lento. Durante la intervención tuvimos en cuenta estos resultados para planear actividades que ayudaran a los estudiantes a ser conscientes de sus discursos y jalonar cambios hacia la producción de textos en lengua de señas más elaborada que tuvieran en cuenta a su interlocutor. Además, como docentes les exigimos a los escolares sordos que fueran más explícitos y usaran formas más elaboradas del discurso durante las tareas asignadas.

Con respecto a los resultados de la intervención pedagógica, en las unidades I y II los estudiantes sordos fueron confrontados con la riqueza que ofrece la lengua escrita. Respecto a la lectura y comprensión de textos con modo narrativo, se observó que empezaron a disfrutar de la lectura, lo que se evidenció con un aumento en la atención y las participaciones, en la cuales hacían predicciones, planteaban hipótesis y expectativas sobre el desenlace de las historias Todo lo anterior incidió en el fortalecimiento de la autoconfianza de cada estudiante.

En la unidad IV, el nivel microestructural, los estudiantes lograron establecer las relaciones y realizar las inferencias gracias al uso de los elementos funcionales de la flecha y los colores. El uso de la flecha facilitó la visualización de los lazos que unen a las proposiciones y los ayudó a establecer las relaciones con un antes y un después. El uso de la flecha y los colores permitieron al estudiante por un lado ver la relación referencial o léxica y por otro lado ver el texto como un tejido; todo lo anterior facilitó que el escolar sordo interactuara con el texto escrito y enriqueciera la segunda lengua.

A continuación presentamos los resultados encontrados en la unidad $V$, nivel superestructural y macroestructural. Como primer resultado destacamos que, la señalización de palabras con colores les facilitó a los estudiantes identificar el campo del conocimiento al que pertenece el texto. Esta práctica ayudó a los escolares a evitar la confusión de palabras por grafías similares, que es frecuente en los estudiantes sordos. 
Otro resultado está relacionado con la lectura y la relectura del texto escrito, ya que esta práctica permite establecer las relaciones microestructurales para mantener el hilo del desarrollo temático y comprenderlo. El tercer resultado es el trabajo de los marcadores textuales. Esto fue un aspecto importante para los escolares sordos, quienes no los conocían y expresaron que antes de la intervención los ignoraban porque desconocían su función.

Un cuarto resultado fue la construcción del mapa textual. Esta estrategia consistió en organizar en el diagrama las proposiciones del texto, según los conectores o marcadores textuales que cumplen la función de distribuir la información textual. Un quinto resultado está relacionado con la identificación de las ideas principales y secundarias. La visualización del mapa textual se convirtió en una macrorregla visual, ya que les facilitó a los escolares sordos identificar la macroestructura del texto. Además se transformaron las creencias y actitudes sobre la lectura del castellano escrito, pues había una concepción previa de que la idea principal de un texto escrito siempre estaba al final.

En general podemos afirmar que, en la medida en que los estudiantes conocieron el funcionamiento de los textos explicativos, cambiaron la actitud negativa hacia el texto escrito y se interesaron por leerlos y comprenderlos.

Por último, con respecto a la fase III, en la Tabla 4 se presentan los datos comparativos de los resultados de la evaluación de la prueba inicial o pretest que se realizó antes de la intervención pedagógica y la prueba final o postest que se realizó después de la intervención. Como se observa en la prueba final o postest, la media de la comprensión de textos explicativos con secuencia comparativa fue de $6.14 / 10$ y la media de la comprensión del texto con secuencia descriptiva fue de 8.29/10. Estos datos confirman los avances que tuvieron los escolares sordos en la lectura y comprensión de textos explicativos.

Ahora, para obtener el mejoramiento de la intervención pedagógica se realizó la siguiente operación, mejoramiento = postest - pretest. Según los datos de la Tabla 4, el mejoramiento es $3.25 / 10$, en términos porcentuales es de $87 \%$.

El proceso de intervención y estos datos cuantitativos nos permiten confirmar que la intervención pedagógica discursiva e interactiva pertinente para los escolares sordos sí facilita la comprensión de textos escritos explicativos con secuencia descriptiva y comparativa en el grupo de escolares que participaron en el experimento.

\section{CONCLUSIONES Y DISCUSIONES}

El diseño y la ejecución de la intervención pedagógica discursiva e interactiva les facilitaron a los estudiantes la lectura y la comprensión de textos explicativos con secuencias descriptiva y comparativa, lo que evidencia que la enseñanza del castellano escrito a los sordos partiendo desde sus necesidades coincide con la zona de desarrollo próximo, pues jalona a través del aprendizaje el desarrollo potencial de

Tabla 4. Datos cuantitativos del pretest y del postest

\begin{tabular}{cccc}
\hline Pretest & Pretest & Postest & Postest \\
\hline Comparativo & Descriptivo & Comparativo & Descriptivo \\
3.89 & 4.00 & 6.14 & 8.29 \\
\hline
\end{tabular}


los procesos inferenciales en relación con los textos escritos.

Los resultados de esta investigación evidencian que es necesario enseñar el castellano a los sordos desde los textos escritos para facilitar el dominio de los géneros secundarios, y accedan al conocimiento, a la ciencia, a la técnica y a los demás bienes de la cultura, como lo ordena la Constitución y se pueda erradicar el analfabetismo.

Dado que este estudio se desarrolló en un horario adicional a la jornada escolar, se recomienda ampliar la intensidad horaria a 10 horas semanales para poder desarrollar una intervención pedagógica como la que aquí se propone y se les permita a los estudiantes sordos aprender el castellano escrito y fomentar la autonomía del escolar sordo. Por esta razón, se debe eliminar la ambigüedad en la asignación del espacio académico en la escuela, es decir, no se debe orientar con la intensidad horaria de la lengua extranjera de los oyentes, pues los colombianos sordos deben aprender la lengua nacional para eliminar las barreras de comunicación con su familia, escuela y comunidad en general, para lo cual se necesitan como mínimo 10 horas semanales.

Las variables independientes relacionadas con los sujetos, como el curso, la edad en que perdieron la audición, la edad en que iniciaron el uso de la lengua de señas en el contexto académico y la edad cronológica no tienen correlación con el nivel de comprensión textual en este grupo de escolares sordos, ni con el pretest ni con el postest. Se comprueba porque los participantes en este estudio tenían entre 14 y 21 años, y habían ingresado a la escuela sin tener el dominio de la primera lengua, eran de diferentes cursos y todos pudieron leer y comprender los textos explicativos con secuencia descriptiva y comparativa, si bien algunos presentaron más dificultad que otros, pero al final todos lograron enfrentarse a los textos escritos, leerlos, comprenderlos y resolver las preguntas de comprensión de manera consciente y autónoma. Este hecho elimina las dudas de algunos docentes que creen imposible que los escolares comprendan textos escritos ingresando a la escuela en extraedad o sin tener la primera lengua.

En esta investigación comprobamos que el enriquecimiento de los niveles textuales en los lectores sordos permitió que se enfrentaran a los textos escritos solos, sin la mediación del intérprete, por lo anterior se recomienda el desmonte del servicio de interpretación en esta asignatura como una exigencia para usar la lengua escrita. Estamos de acuerdo con el servicio de interpretación en la escuela, pero no en la clase de castellano ni en las evaluaciones escritas.

Identificar el tipo de código que utilizan los estudiantes para orientar el significado, teniendo en cuenta las investigaciones de Bernstein (1983), fue clave para diseñar y ejecutar la intervención, pues nos guió para partir de lo conocido, la lectura de proposiciones cercanas al contexto inmediato de los estudiantes y jalonar el desprendimiento de la inmediatez hacia los textos escritos explicativos, que son independientes del contexto inmediato y más elaborados.

Finalmente, para este grupo de escolares sordos, el mapa textual se convirtió en una macrorregla visual, ya que les facilitó ver la jerarquía de las ideas para identificar las ideas principales y secundarias.

Los resultados de esta investigación nos permiten sugerir que es necesario que tanto el Ministerio de Educación Nacional como el Instituto Nacional para Sordos lideren la construcción de los lineamientos para la enseñanza del castellano escrito como segunda lengua en colaboración con los docentes, con el propósito de dar las directrices para que la población de estudiantes sordos accedan a la cultura letrada como todos los colombianos.

\section{RECONOCIMIENTOS}

Este artículo es resultado de la investigación desarrollada en el marco del Doctorado Interinstitucional en Educación, Universidad del Valle. 


\section{REFERENCIAS}

Álvarez, D. (2002). Incidencia de la explicitación de las formas de organización superestructural de los textos expositivos en lengua castellana en la comprensión textual de un grupo de estudiantes de la Universidad del Valle (tesis de maestría para optar al título de Magíster en Lingüística). Escuela de Ciencias del Lenguaje. Cali: Universidad del Valle.

Bajtín, M. (1982). La estética de la creación verbal. México: Siglo XXI.

Bernstein, B. (1983). La educación no puede suplir las fallas de la sociedad. Lenguaje y sociedad. Centro de Traducciones. Cali: Universidad del Valle.

Hernández, F. (2002). Incidencia de una intervención pedagógica en la comprensión y producción de textos argumentativos polifónicos desde el discurso referido en un grupo de estudiantes de la Universidad del Valle (tesis de maestría para optar al título de Magíster en Lingüística). Escuela de Ciencias del Lenguaje. Universidad del Valle, Cali.

Martínez, M. C. (2015). Análisis del discurso. Cohesión en español. Coherencia y estructura semántica de los textos académicos. Cátedra UNESCO Lectura y Escritura. Cuarta edición. Cali: Universidad del Valle.

Martínez, M. C. (2004). El procesamiento multinivel del texto escrito. Lenguaje, 32, 7-28.

Martínez, M. C. (2002). Propuestas de intervención pedagógica para la comprensión y producción de textos académicos: expositivos y argumentativos. Cali: Universidad del Valle.
Martínez, M. C. (1985). Orientación del significado y clase social en un contexto narrativo. La referencia. Lenguaje, 15, 19-36.

Ministerio de Educación Nacional. (2000). Resolución 1515. Por la cual se establecen los requisitos para la prestación del servicio educativo para los estudiantes sordos.

Plaza, L. M. (2015). Incidencia de una intervención pedagógica para enseñar a leer y comprender textos escritos explicativos en lengua castellana a estudiantes sordos de educación básica y media. (tesis doctoral para optar al título de Doctor en Educación). Instituto de Educación y Pedagogía. Cali: Universidad del Valle.

Skliar, C. (1997). La educación de los sordos. Mendoza: Editorial Universidad Nacional de Cuyo.

Rodríguez de Salazar, N. (Coord.). (2009). Manos y pensamiento: inclusión de estudiantes sordos a la vida universitaria: Socialización y réplica de la experiencia. Bogotá: Universidad Pedagógica Nacional.

Van Dijk, T. (1978). La ciencia del texto. Buenos Aires: Paidós.

Van Dijk, T. \& Kintsch, W. (1978). Towards a model of discourse comprehension and production. Psychological Review, 85, 363-394.

Vidal Abarca, E. (1991). Programa para la enseñanza de la comprensión de ideas principales de textos expositivos. Infancia y Aprendizaje, 49, 276-296

Vygotski, L. (1983/2001). Pensamiento y lenguaje. Obras escogidas 2. España: Editorial Aprendizaje Visor. 